Working Paper No. 604, 2003

Endogenous Asset Ownership Structures in Deregulated Markets

by Pehr-Johan Norbäck and Lars Persson

IUI, The Research Institute of Industrial Economics

P.O. Box 5501

SE-114 85 Stockholm

Sweden 


\title{
Endogenous Asset Ownership Structures in
}

\author{
Deregulated Markets
}

\author{
Pehr-Johan Norbäck and Lars Persson* \\ Research Institute of Industrial Economics
}

October 27, 2003

\begin{abstract}
This paper determines the equilibrium ownership structure in an emerging market deregulated by privatization and investment liberalization. It is shown that bidding competition in the privatization stage is necessary but not sufficient for reaching an efficient equilibrium market structure. Competition in the ensuing entry stage is also necessary. Otherwise, one firm can induce another to take the role of the weak firm in the subsequent product market competition, by making concessions in the bidding in the privatization auction. It is also shown that Employment Guarantees may "help" the buyer of the privatized firm "abstain" from investing and by that creating a less competitive market structure.
\end{abstract}

Keywords: Privatization, Ownership, FDI, Auctions, Employment Guarantees. JEL classification: D44, F23, L1, L4

${ }^{*}$ We are grateful for helpful discussions with Yongmin Chen, Henrik Horn and participants at IUIseminars. Thanks also to Christina Lönnblad for improving the language. Financial support from the Marianne and Marcus Wallenberg Foundation, and Tom Hedelius' and Jan Wallander's Research Foundations is gratefully acknowledged. Email: larsp@iui.se. 


\section{Introduction}

During the last decades we have witnessed large privatizations and deregulation programs all over the world. ${ }^{1}$ These programs has been carried out in many different sectors of the economy, including the manufacturing sector, utility and communication services and the financial sector. ${ }^{2}$ An important ingredient in many of these programs has been the use of auctions to allocate productive assets to the most efficient owner and thereby contribute to the creation of efficient market structures. However, it is a fear that many of these privatization and deregulation programs have not lead to a fast creation of efficient market structures. For instance, while recent empirical evidence shows the long-run impact of privatization on firms' productivity in transition countries to have been mainly positive, it has also been acknowledged that the positive impact has taken time ${ }^{3}$ and that ownership identity is of importance. ${ }^{4}$ For instance, new investments in and radical reorganizations of product lines and processes were - at least in the early stages -only observed in foreignowned enterprises. ${ }^{5}$.

In this paper we argue, that the obstacle to the creation of efficient market structures is consistent with an inefficiency in asset ownership allocation, depending on a non-obvious weakness in privatization design. More specifically, we show that if a privatization takes place through an auction ${ }^{6}$, an inefficient owner might obtain the state assets even though

\footnotetext{
${ }^{1}$ Privatization and deregulation activities are driven by factors such as a general trend of reducing the state in the economy, budgetary constraints, a need for attracting investments and a combination of technological change, liberalization and globalization of product and financial markets (OECD (2000)).

${ }^{2}$ Many countries also announce substantial forthcoming privatizations. Planned privatizations suggest that privatization proceeds will remain strong through continued activitities in Europe and Asia. Examples of countries with large privatization plans are China, Japan, Portugal, Thailand and Turkey (OECD (2000)).

${ }^{3}$ Estrin (2002).

${ }^{4}$ Djankel and Murrell (2000) conclude: "Privatization to workers is detrimental, privatization to diffuse individual owners has no effect and privatization to funds or foreigners has a large positive effect."

${ }^{5}$ Carlin and Landesmann (1997).

${ }^{6}$ In practise, different types of measures have been used to privatize former state-owned enterprises.
} 
more efficient owners are present as potential buyers. In the model, a state-owned enterprise is initially located in the market. It is assumed that the government will liberalize the market by: (i) selling the state assets, and (ii) allowing for new plants to be opened by private investors, i.e. abolishing investment restrictions. In the first stage, the state assets are sold at an auction, with two potential buyers. There is an efficient owner, for example a firm which firm specific assets match well with the assets for sale, the most efficient firm in a related industry or the market leader in the world market. There is also an inefficient owner, which could be a less efficient firm, a firm which firm-specific assets does not match well with the assets for sale, former worker or the former management team, or an inactive pension fund. The efficient owner is assumed to face lower variable production costs when using the state assets due to its access to superior technology or knowledge. In the second stage, the owners may invest by setting up a new plant, where the efficient technology is used. Here, it is assumed that the inefficient owner will now have the time to introduce a more updated or appropriate technology, and may do so if this is profitable. In the third stage, the owners compete in Cournot fashion where the inefficient owner faces a higher production cost if only using the state assets in its production.

We show that for a sufficiently large difference in variable production cost when using state assets, the inefficient owner obtains the state assets, whereas when such cost differences are low, the efficient owner obtains the state assets. The reason why the efficient owner chooses costly investment in new assets and lets the inefficient owner obtain the state assets, is that it will then face a competitor with higher costs in the ensuing product market competition. As we show, this follows from the inefficient owner investing in new assets, if and only if not obtaining the state assets. Moreover, the inefficient owner benefits Several western countries employed various kinds of auctions to sell state-owned enterprises to the highest bidder. In some transition countries, a substantial fraction of the shares of all firms were given to the general population for free. Most privatization programs combined several elements of these basic methods. See Schmidt and Schnitzer (1997). 
from "taking on" a weak market position, since it is compensated by a low acquisition price. However, when the inefficient owners costs are low, the efficient owner obtains the state assets, since the inefficient owner will now be a relative tough competitor also when using the state assets. This result illustrates how the auction "helps" the owners achieve the, for them, most advantageous market structure. By making concessions in the bidding, one owner can induce the other to take on the role of the weak owner in the subsequent product market competition. ${ }^{7}$

It is also shown that when the number of efficient owners participating in the investment game increases, the risk of having an inefficient buyer decreases. The reason is that an efficient owner then faces the risk of not being able to enter the market at all, when not entering through acquisition. It has been acknowledged that traditional antitrust concerns such as preventing collusive, predatory and entry deterring behavior are important for successfully designing an auction in practise. ${ }^{8}$ Here, we show another possible type of collusive behavior that might be a problem: when the auction is followed by an entry game into the same market bidding competition in the privatization stage is necessary but not sufficient, competition in the investment entry stage is also required. Otherwise, the auction could be used as a collusive devise to avoid tough product market competition.

The paper also throws some light on other issues in relation to privatizations. A major concern in privatization programs is the protection of employment. The practice of "Employment guarantees" when selling former state assets in order to ensure future employment has been fairly widespread. ${ }^{9}$ However, it is shown that Employment Guarantees can be counterproductive in the sense of implying that a less efficient owner obtains the

\footnotetext{
${ }^{7}$ The importance of creating a profitable market structure and selecting the right competitor has been acknowledged in the business literature. For instance, Porter (1998) writes: "While competitors can surely be threats, the right competitors can strengthen rather than weaken a firm's competitive position in many industries".

${ }^{8}$ See Klemperer (2002).

${ }^{9}$ For instance, in Eastern Germany, the Treuhandanstalt bargained on the terms of trade and negotiated employment and investment guarantees (Schmidt and Schnitzer (1997).
} 
privatized firm. The intuition is that the Employment Guarantee helps the buyer of the state-assets "abstain" from investing, thereby creating a less competitive market structure with less total employment.

To our knowledge, no paper in the theoretical privatization literature or auction literature evaluates the selling of scarce assets in a situation where asymmetric potential buyers can invest in new capital and compete in an oligopoly. ${ }^{10}$

The model is spelled out in Section 2 and in Section 3, we derive the equilibrium ownership structure. In Section 4, policy issues are discussed and Section 5 concludes. Finally, most proofs appear in the Appendix.

\section{The Model}

Consider a country where the market has previously been served by a state enterprise, but which will now be open to private investments. It is assumed that the government will liberalize the market through a program with two distinct measures: (i) selling the state assets, and (ii) allowing for new plants to be opened by abolishing investment restrictions.

As illustrated in figure 2.1, the interaction takes place in three stages. In the first stage, the government sells the state assets, denoted $k_{S}$, in one piece at an auction where the two investors are the potential buyers. There is an efficient owner, owner $e$, for example the most efficient firm in a related industry or the market leader in the world market. There is also an inefficient owner, owner $i$, which could be a less efficient firm, a firm which firm-

\footnotetext{
${ }^{10}$ For overviews of the privatization literature see, for instance, Schmidt and Schnitzer (1997) and Vickers and Yarrow (1991).

Few papers in the theoretical auction literature deal with the situation where the potential buyers are ex-ante asymmetric firms competing in an oligopoly. Exceptions are, among others, Chen (2000), Ghemawat (1990), Jehiel and Moldovanu (1996a, 2000), and Krishna (1993). However, to our knowledge, no paper deals with determining the equilibrium buyer in a situation where the potential buyers could also invest in new capital. An exemption is Norbäck and Persson (2003). However, the focus in that paper is to study the pattern of foreign and domestic acquisitions in an international oligopoly.
} 


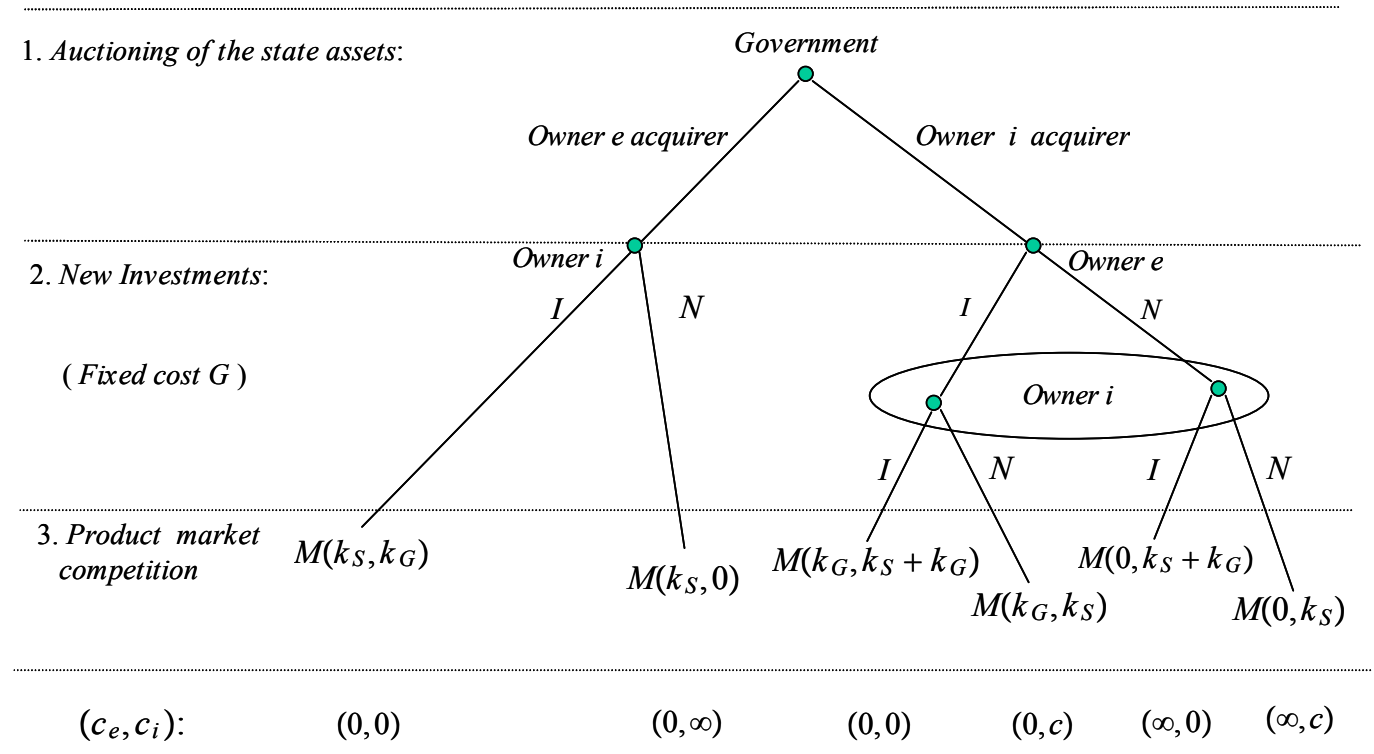

Figure 2.1: The structure of the model.

specific assets does not match well with the assets for sale, former worker or the former management team, or an inactive pension fund. The efficient owner is assumed to face lower variable production costs when using the state assets due to its access to superior technology or knowledge. In the second stage, the owners may invest by setting up a new plant, denoted $k_{N}$, where the efficient technology is used. Here, it is assumed that the inefficient owner will now have the time to introduce a more updated or appropriate technology, and may do so if this is profitable. To simplify the analysis, investment is assumed to be a dichotomous choice. Finally, in the third stage, owners compete in Cournot fashion in the product market.

Section 2.1 describes the oligopoly market, and the following section presents the investment game and the privatization procedure.

\subsection{The Oligopoly market}

In the third stage, owners compete in oligopoly fashion in a homogenous good market. Let $\pi_{h}^{D}\left(c_{h}, c_{j}\right)$ denote the the reduced-form duopoly profit for owner $h=\{e, i\}$, when owner $h$ 
faces a variable cost $c_{h}$ and owner $j$ faces a variable cost $c_{j}$. We assume firm $h$ 's profit to be decreasing in its own marginal cost, and increasing in that of its rival i.e.

Assumption 1: $\frac{\partial \pi_{h}^{D}\left(c_{h}, c_{j}\right)}{\partial c_{h}}<0, \frac{\partial \pi_{h}^{D}\left(c_{h}, c_{j}\right)}{\partial c_{j}}>0$

We define $c^{\max }$ as the $c$ satisfying $q_{h}(c, 0)=0$ and $\pi_{h}^{M}\left(c_{h}\right)$ as denoting the monopoly profit when the monopolist faces a production cost, $c_{h}$. Assumption 1 should be fulfilled in most oligopoly models. In the appendix, we show that our results derived below extend into Cournot as well as Bertrand competition.

In Lemma 1, it is shown that the state assets will be sold at the auction in equilibrium. As illustrated by Figure 2.1, this implies that six different market structures are to be considered. To keep track of these, we denote the market structure as $M\left(k_{e}, k_{i}\right)$. For example, a market structure where owner $e$ owns the state assets and owner $i$ owns new assets is denoted $M\left(k_{S}, k_{N}\right)$. The last row in figure 2.1 refers to the owners' marginal costs in the different market structures. The inefficient owner, $i$, is assumed to face a variable production cost, $c$, when only owning state assets, whereas the efficient owner, $e$, is then assumed to produce at a zero cost. An owner $h$ possessing one unit of new assets is assumed to produce at a zero variable cost. Hence, we are taking the simplification that efficient and inefficient owners only differ in their ability to use state assets. However, it can be shown that the results also hold for differences in the ability to use (or differences in the cost of investing into) new assets. This is disussed more in Section 4.1.2.

\subsection{The greenfield investments}

At this stage, the owners might undertake investment at a fixed cost, $G$. An owner (firm) then faces a zero production cost. To solve the investment game, we transform the game in Figure 2.1 into its normal form. This is done in Figure 2.2, where Figure 2.2(i) depicts the investment game when the inefficient owner $i$ obtains the state assets, whereas Figure 2.2(ii) depicts the corresponding game with the efficient firm $e$ as the acquirer. In the 


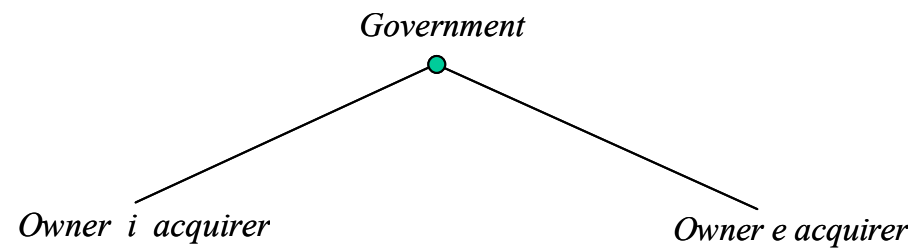

$i$ :

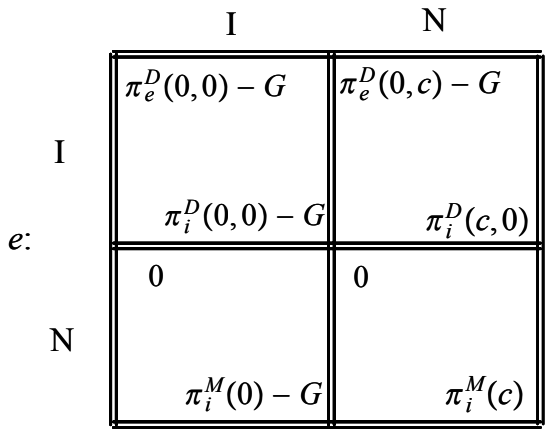

(i): Investment game when owner $i$ acquires the state assets $i$ :

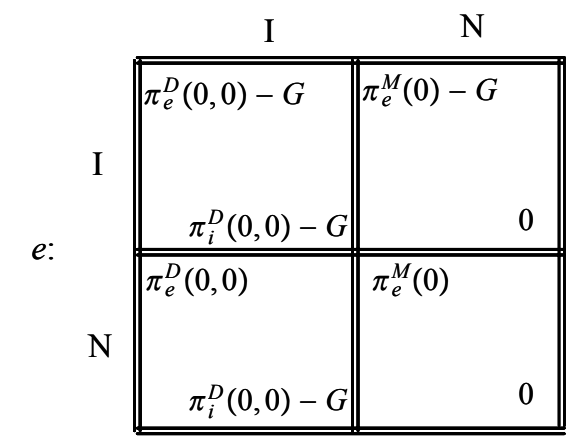

(ii): Investment game when owner $e$ acquires the state assets

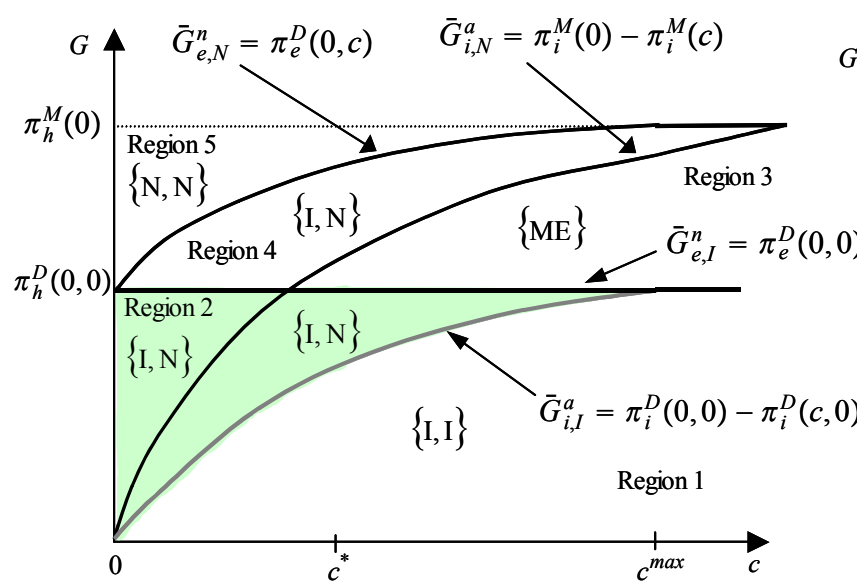

(iii): Nash-Equilibria for the Investment game when $i$ acquires the state assets

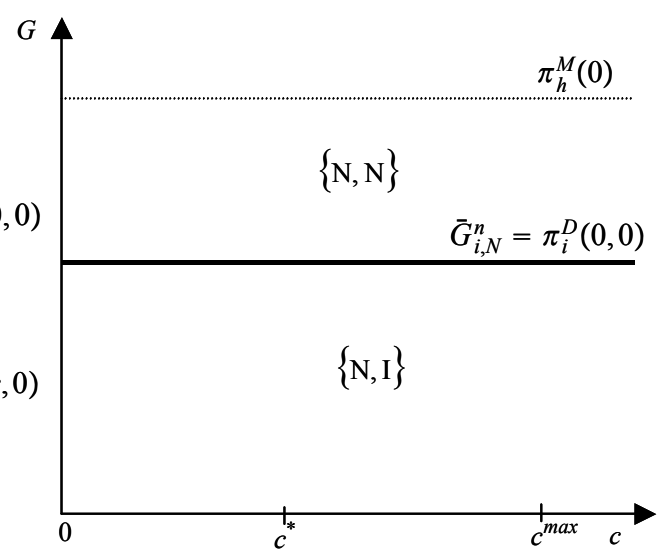

(iv): Nash-equilibria for the Investment game when $e$ acquires the state assets

Figure 2.2: Solving the investment game. 
Appendix, we derive the Nash-Equilibria ${ }^{11}$ which are shown in Figures 2.2(iii)-(iv). For example, $\{I, N\}$ denotes the Nash-Equilibrium where owner $e$ is investing greenfield $(I)$, whereas the inefficient owner $i$ is not $(N)$.

Turning to Figure 2.2(iv), it follows directly that the efficient owner $e$, as the buyer of the state assets, has no incentive to invest. The inefficient owner $i$ invests as long as the investment costs are recovered. Given that firm $e$ is not investing (indicated by subscript $N), \bar{G}_{i, N}^{n}=\pi_{i}^{D}(0,0)$ is the critical value of the investment cost $G$, such that owner $i$, when not acquiring the state assets (indicated by superscript $n$ ), is indifferent between investing and not.

Turning to the case where the inefficient owner $i$ obtains the state assets in Figure 2.2(iii), $\bar{G}_{i, I}^{a}=\pi_{i}^{D}(0,0)-\pi_{i}^{D}(c, 0)$ denotes the threshold value of the investment cost for the inefficient owner $i$ (where $a$ now indicates the acquirer), given that the efficient owner $e$ has invested (indicated by subscript $I$ ). Above this threshold, the inefficient owner $i$ will not find it profitable to invest in additional new assets when owning the state assets. Similarly, we define $\bar{G}_{i, N}^{a}=\pi_{i}^{M}(0)-\pi_{i}^{M}(c), \bar{G}_{e, I}^{n}=\pi_{e}^{D}(0,0)$ and $\bar{G}_{e, N}^{n}=\pi_{e}^{D}(0, c)$.

\subsection{The privatization procedure}

In order to focus on the market forces as the determinants of the equilibrium buyer and the equilibrium market structure, we assume that the government sells the state assets to the highest bidder at an auction. ${ }^{12}$ More specifically, the privatization process is depicted as an auction where the two owners simultaneously post bids and the bidder with the highest bid obtains the state assets. The winning buyer pays an amount equal to his bid.

\footnotetext{
${ }^{11}$ Risk dominance is used to select between multiple equilibria, indicated $\{\mathrm{ME}\}$ in Figure 2.2(iii).

${ }^{12}$ In practise, different types of measures have been used to privatize former state-owned enterprises. Several western countries employed various kinds of auctions to sell state-owned enterprises to the highest bidder. In some transition countries, a substantial fraction of the shares of all firms was given to the general population for free. In Eastern Germany, the Treuhandanstalt bargained on the terms of trade and negotiated employment and investment guarantees. Most privatization programs combined several elements of these basic methods. See Schmidt and Schnitzer (1997).
} 
The auctions will be solved for Nash equilibria in undominated pure strategies. ${ }^{13}$

Let us now turn to the owners' valuations of an arbitrary distribution of the state assets. Generally, these valuations do not only depend on the identity of owner $h$, but also on the identity of the owner that will obtain the assets if owner $h$ does not. Some notation is required in order to define an owner's valuation. We let $\pi_{h j}$ denote the profit made by owner $h$ when owner $j$ has acquired the state assets and $\pi_{h h}$ the profit made by owner $h$ when it has acquired the state assets itself. Then, the valuation for owner $h, v_{h j}$, is defined as

Definition 1. $v_{h j} \equiv \pi_{h h}-\pi_{h j}$.

Lemma 1 identifies the equilibrium buyer in the auction:

Lemma 1. Let owner $h$ be the owner with the highest valuation. The state assets are then acquired by owner $h$, at a price equal to the other owner's, owner $j$ 's, valuation of obtaining the state assets instead of owner $i, v_{j h}$.

Proof. See the Appendix.

\section{Asset ownership}

In this section we determine the equilibrium ownership structure and study how it depend on difference in cost efficiency and investment costs. The game is solved backwards, by forming the respective owners' valuations based on the outcome of the investment game in Figures 2.2(iii)-(iv).

\footnotetext{
${ }^{13}$ There is assumed to be a smallest monetary unit, denoted $\varepsilon$. We assume ties to be randomly broken, and all equalities in valuations to be ruled out. The smallest amount $\varepsilon$ is chosen such that all inequalities are preserved, if $\varepsilon$ is added or subtracted.
} 


\subsection{The equilibrium asset ownership structure}

One more definition is required to proceed. To this end, consider the situation where only the non-acquirer will investment in new assets. Let $c^{*}$ be the value of the inefficient owner $i$ :s production cost satisfying the following equality: $v_{e i}=\pi_{e}^{D}(0,0)-\left(\pi_{e}^{D}(0, c)-G\right)=$ $\pi_{i}^{D}(c, 0)-\left(\pi_{i}^{D}(0,0)-G\right)=v_{i e}$. Thus, $c^{*}$ is the production cost of owner $i$, at which owner $e$ 's and owner $i$ 's valuations of the state assets coincide, given that only the non-acquirer invests in new assets. In Table 3.1, we derive the owners' valuations, the equilibrium buyer, the equilibrium market structure and the equilibrium auction price.

Table 3.1: Deriving the Equilibrium Market Structure (EMS).

\begin{tabular}{|c|c|c|c|c|c|}
\hline & Region 1: & Region 2: & Region 3: & Region 4: & Region 5: \\
\hline Def: & $G<G_{i, I}^{a}$ & $\begin{array}{r}G_{i, I}^{a}<G<G_{e, I}^{n} \\
0<c<c^{\max }\end{array}$ & $G_{e, I}^{n}<G<G_{i, N}^{a}$ & $G_{i, N}^{a}<G<G_{e, N}^{n}$ & $G>G_{e, N}^{n}$ \\
\hline$v_{i e}:$ & 0 & $\begin{array}{l}\pi_{i}^{D}(c, 0)- \\
{\left[\pi_{i}^{D}(0,0)-G\right]}\end{array}$ & $\pi_{i}^{M}(0)-G$ & $\pi_{i}^{D}(c, 0)$ & $\pi_{i}^{M}(c)$ \\
\hline$v_{e i}:$ & $G$ & $\begin{array}{l}\pi_{e}^{D}(0,0)- \\
{\left[\pi_{e}^{D}(0, c)-G\right]}\end{array}$ & $\pi_{e}^{M}(0)$ & $\begin{array}{l}\pi_{e}^{M}(0)- \\
{\left[\pi_{e}^{D}(0, c)-G\right]}\end{array}$ & $\pi_{e}^{M}(0)$ \\
\hline EB: & $e$ & $\left\{\begin{array}{l}e: c<c^{*} \\
i: c>c^{*}\end{array}\right.$ & $e$ & $e$ & $e$ \\
\hline $\mathcal{A}:$ & 0 & $\left\{\begin{array}{l}v_{i e}: c<c^{*} \\
v_{f i}: c>c^{*}\end{array}\right.$ & $v_{i e}$ & $v_{i e}$ & $v_{i e}$ \\
\hline EMS: & $M\left(k_{S}, k_{G}\right)$ & $\left\{\begin{array}{l}M\left(k_{S}, k_{G}\right): c<c^{*} \\
M\left(k_{G}, k_{S}\right): c>c^{*}\end{array}\right.$ & $M\left(k_{S}, 0\right)$ & $M\left(k_{S}, 0\right)$ & $M\left(k_{S}, 0\right)$ \\
\hline$c_{e}, c_{i}$ & $\{0,0\}$ & $\left\{\begin{array}{l}\{0,0\}: c<c^{*} \\
\{0, c\}: c>c^{*}\end{array}\right.$ & $\{0, \infty\}$ & $\{0, \infty\}$ & $\{0, \infty\}$ \\
\hline
\end{tabular}


Proposition 1. (a) When investment costs are high, the efficient owner e obtains the state assets. (b) At intermediate investment costs and sufficiently large differences in variable production cost between the efficient owner $e$ and the inefficient owner $i$ when using state assets, the inefficient owner $i$ obtains the state assets. (c) At low investment costs, the efficient owner e obtains the state assets.

\section{Proof. See the Appendix.}

Proposition 1, which is illustrated in Figure 3.1(ii) contains several noteworthy features.

First, in the case where greenfield costs are high, i.e. when the buyer of the state assets becomes a monopolist, the Lemma shows that owner $e$, the efficient owner, obtains the assets. The reason is that a more efficient monopolist is willing to pay more for becoming the monopolist than an inefficient monopolist.

Second, in the case where greenfield costs are medium high, either owner $e$ or owner $i$ obtains the assets, depending on the variable production cost difference between them. The reason why the efficient owner $e$ chooses costly investment in new assets and lets the inefficient owner $i$ obtain the state assets when the difference in variable production cost is high, is that it will then face a competitor with higher costs in the ensuing product market competition. However, when the inefficient owners costs are low, the efficient owner obtains the state assets, since the inefficient owner will now be a relatively tough competitor also when using the state assets.

Third, in the case where greenfield costs are low, owner $e$ obtains the state assets: The reason is that if owner $e$ obtains the state assets it will not invest greenfield. This implies that owner $e$ 's willingness to pay is $G$. If the inefficient owner $i$ obtains the state assets, both the inefficient (as well as the efficient owner) will invest in new assets and thus, the inefficient owner's willingness to pay is zero. ${ }^{14}$

\footnotetext{
${ }^{14}$ These results hold, for instance, in a Cournot model with homogeneous products, where firms either face concave or strictly concave demand, $P^{\prime}(Q)<0$ and $P^{\prime \prime}(Q) \leq 0$. Our results also extend to Bertrand competition with differentiated goods, using the model of Deneckere and Davidson (1985), where firm $h$ faces the demand $q_{h}=a-P_{h}-\gamma\left(P_{h}-\frac{1}{2}\left(P_{h}+P_{j}\right)\right)$. For further details, see the Appendix.
} 


\subsubsection{Why do large cost differences lead to the inefficient owner obtaining the state assets?}

First, note that the auction mechanism implies that the owner with the highest valuation obtains the state assets. Then, note that $v_{h j}>v_{j h}$ iff $\pi_{h h}+\pi_{j h}>\pi_{j j}+\pi_{h j}$, so that $v_{h j}>v_{j h}$ iff $\Pi_{h}>\Pi_{j}$, where $\Pi_{h}$ is the aggregate profit when owner $h$ obtains the state assets and $\Pi_{j}$ is the aggregate profit when owner $j$ obtains them. Thus, through the auction mechanism, owners will choose the buyer whose possession of the state assets will lead to the highest aggregate profit. It turns out that maximum aggregate profit is not always the most cost efficient market structure. To see why, we examine how the level of costs for the inefficient owner $c$ affects the aggregate profits in a duopoly.

The aggregate profit under inefficient ownership is given by $\Pi_{i}(c)$, corresponding to the U-shaped curve in figure 3.1(i). Note that this aggregate profit can then be expressed as $\Pi_{i}(c)=P\left(q_{i}+q_{e}\right) q_{i}+P\left(q_{i}+q_{e}\right) q_{e}-c q_{i}$. As shown in the Appendix, under Cournot competition, differentiating $\Pi_{i}$ with respect to $q_{i}, q_{e}$, and $c$ and using the foc's yields:

$$
\frac{d \Pi_{i}}{d c}=\frac{d Q}{d c} P^{\prime} q_{e}+\frac{d q_{e}}{d c} c-q_{i}
$$

The first term in Equation (3.1) captures the anti-competitive effect: an increased cost induces the inefficient owner to be less aggressive in the product market, which increases the revenues for the efficient owner. The second term reflects the decrease in total production costs, as the efficient owner steals business from the inefficient owner, an effect referred to as the business stealing effect. The third term, the direct production cost effect, reduces the aggregate profits relative to the initial position, as the inefficient owner faces higher production costs.

Whether aggregate profits are maximized with the efficient or the inefficient owner as the buyer, depends on the balance between the incentive to form $\Pi_{e}(0)$ to avoid the higher production cost, and the anti-competitive and business stealing incentive to form $\Pi_{i}(c)$. Comparing $\Pi_{e}(0)$ and $\Pi_{i}(c)$ in Figure 3.1(i), we can state the following Lemma, giving rise to the market structure in the shaded Region 2 of Figure 3.1(ii). 


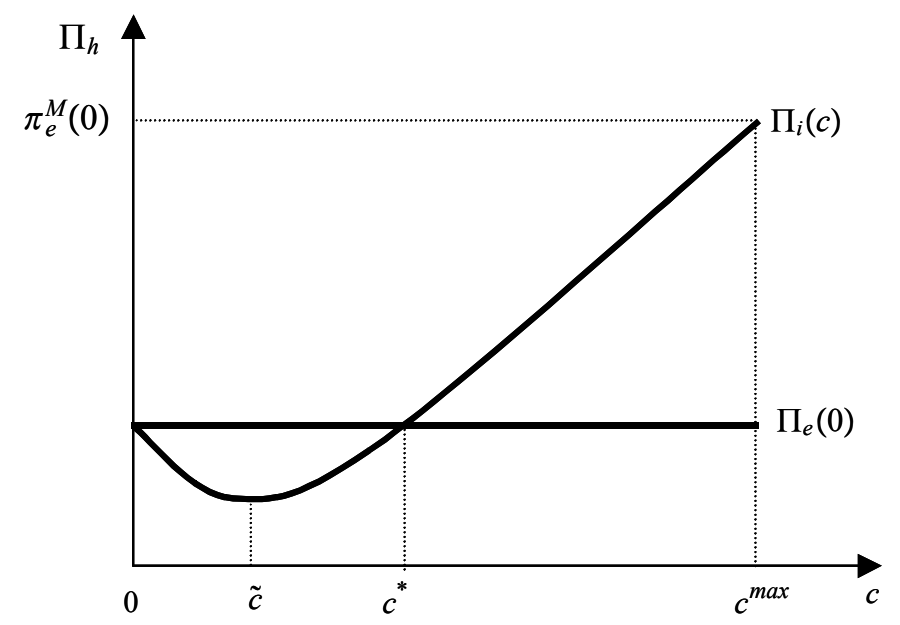

(i) Aggregate profits in Region 2:

$G_{i, I}^{a}<G<G_{e, I}^{n}$
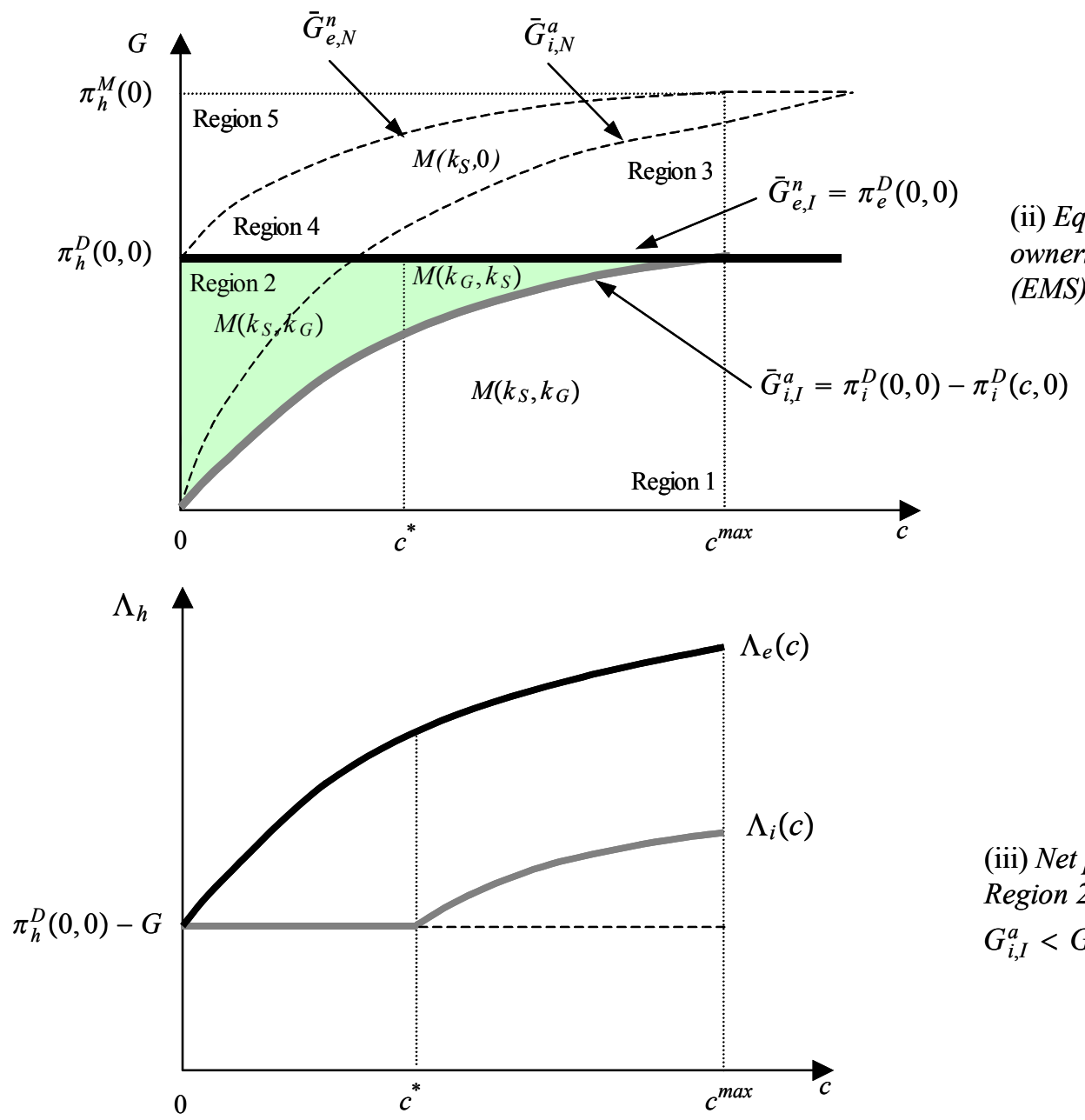

(iii) Net profits in

Region 2:

$G_{i, I}^{a}<G<G_{e, I}^{n}$

Figure 3.1: The Equilibrium Market Structure (EMS). 
Lemma 2. (i) $\Pi_{e}>\Pi_{i}$ when $c<c^{*}$. (ii) $\Pi_{i}>\Pi_{e}$ when $c>c^{*}$.

Proof. See the Appendix

In general, the auction mechanism takes into consideration the "opportunity cost" of an acquisition. For instance, it might be the case that "allocating" the asset to one owner might create the most efficient acquirer, although the "opportunity cost" of creating this acquirer may be higher, since this may imply that a more attractive non-acquirer is foregone. Since the auction mechanism takes these aspects into consideration, the most efficient acquirer is not necessarily created.

\subsubsection{Net profits and cost differences}

Let us now turn to how the different owners' net profits depend on the differences in variable production costs. Then, define the net-profits as $\Lambda_{h}\left(c_{h}, c_{j}\right)=\pi_{h}^{D}\left(c_{h}, c_{j}\right)-\Phi_{h}$, where $\Phi_{h}$ are firm $h$ 's fixed costs in the form of the acquisition price $A$ and/or fixed investment costs $G$. In Figure 3.1 (iii), the net profits of owners $e$ and $i$, respectively, are depicted in the case of high greenfield costs.

First, consider the situation where the inefficient owner $i$ 's costs are relatively low. In this interval, owner $e$, obtains the assets and owner $e$ 's net profit increases in the inefficient owner $i$ 's costs. The reason is that the efficient owner $e$ 's equilibrium product market profit is unaffected by owner $i$ 's cost, but the inefficient owner $i$ 's willingness to pay decreases since its value of the assets decreases. The inefficient owner $i$ 's net profit is thus unaffected since it does not affect the product market profit.

Second, consider the situation where the inefficient owner $i$ 's costs are relatively high. In this interval, the inefficient owner $i$ obtains the assets and both the efficient owner $e$ 's and the inefficient owner $i$ 's net profit increases in owner $i$ 's costs. The reason is that despite the inefficient owner $i$ 's product market profit decreases, the efficient owner $e$ 's willingness to pay (and hence the acquistion price), decreases even more.

The latter follows from the inefficient owner investing in new assets if and only if 
not obtaining the state assets. Hence, the inefficient owner benefits from "taking on" a weak market position, since it is compensated by a low acquisition price. This is also illustrated in Figure 3.1(iii), where it can be noted that both firms earn net-profits exceeding the profits made in a case where both firm utilize new assets, i.e. they earn positive profits compared to a (hypothetical) case where the state assets are liquidated, $\Lambda_{e}(0, c)>\pi_{e}^{D}(0,0)-G$ and $\Lambda_{i}(c, 0)>\pi_{i}^{D}(0,0)-G$ for $c>c^{*}$.

\section{Policy}

In previous section, we have shown that the buyer's identity and the auction price in the present analysis are intricately dependent on detailed firm characteristics. This implies that the optimal design of policy is very complicated and requires considerable information. In Section 4.1, we therefore illustrate two different mechanisms for competition to promote an efficient outcome in the auction. In Section 4.2 we study how labor protection policies in practise may affect the buyer's identity and the selling price in the privatization.

\subsection{Competition and efficient ownership}

In this section, we show how competition will decrease the possibility for the auction is used by the owners as a collusive devise to achieve a less competitive market structure. This involves extending the model to more than two (asymmetric) owners. Deriving a full solution to such an extended model is very involved. Therefore, we will sketch two different mechanisms through which competition will promote an efficient outcome.

\subsubsection{Strengthening competition for the market}

Competition for the market may promote efficiency. Suppose that there are $E$ symmetric, efficient, owners and $\mathcal{I}$ symmetric, inefficient, owners competing to enter the emerging market, either by acquiring the state assets or investing greenfield. As above, inefficient owners face a marginal cost, $c$, when acquiring state assets and not investing, whereas 
investing gives a zero marginal cost, which is also the marginal cost for efficient owners.

Throughout the analysis in this section, we retain the assumption that it is only profitable for the non-acquirer to invest in new assets, that is, we remain in the parameter setting corresponding to that of Region 2 in Figure 3.1(ii). We assume that the probability of succeeding in investing, conditional on not acquiring the state assets is $\rho(M)=\frac{1}{M-1}$, where $M=E+\mathcal{I}$, and where limited entry may be caused by a combination of insufficient demand, fixed costs and imperfect knowledge of the market, all of which can be avoided by an acquisition. ${ }^{15}$ Let $\pi_{h}\left(c_{h}, c_{j}\right)$ be the (duopoly) product market profit for owner $h$ facing the marginal cost $c_{h}$ when the marginal cost of $h$ 's competitor is $c_{j}$. Since there are two types of owners, there are four valuations to consider. $v_{i i}\left(v_{i e}\right)$ is the value for an inefficient owner when an inefficient (efficient) owner would otherwise obtain the state assets. $v_{e e}\left(v_{e i}\right)$ is the corresponding values for an efficient owner. The valuations can then be written as in table 4.1 .

Table 4.1: Valuations in the extended model.

\begin{tabular}{ll}
\hline \hline Valuation: & Definition: \\
\hline$v_{i i}:$ & $\pi_{i}(c, 0)-\rho(M)\left[\pi_{i}(0, c)-G\right]$ \\
$\tilde{v}_{i e}:$ & $\pi_{i}(c, 0)-\rho(M)\left[\pi_{i}(0,0)-G\right]$ \\
$\tilde{v}_{e e}:$ & $\pi_{e}(0,0)-\rho(M)\left[\pi_{e}(0,0)-G\right]$ \\
$\tilde{v}_{e i}:$ & $\pi_{e}(0,0)-\rho(M)\left[\pi_{e}(0, c)-G\right]$ \\
\hline \hline
\end{tabular}

It follows directly from our assumptions on marginal costs that product market profits can be ranked as follows: $\pi_{h}(0, c)>\pi_{h}(0,0)>\pi_{i}(c, 0)>0$. This, in turn, implies that there are only two possible orderings of the valuations to consider:

It follows that, under inequality $I 1$, the unique equilibrium is that of an efficient owner $e$ acquiring the state assets. However, multiple equilibria exist under $I 2$ : one is that an

\footnotetext{
${ }^{15}$ Our results in this section can also be extended beyond assuming duopoly in the product market competition. Proofs are available from the authors.
} 
Table 4.2: Valuations in the extended model.

\begin{tabular}{lll}
\hline \hline Inequality & Definition & EB \\
\hline$I 1$ & $\tilde{v}_{e e}>\tilde{v}_{e i}>\tilde{v}_{i e}>\tilde{v}_{i i}$ & $e$ \\
$I 2$ & $\tilde{v}_{e e}>\tilde{v}_{i e}>\tilde{v}_{e i}>\tilde{v}_{i i}$ & $e$ or $i$ \\
\hline \hline
\end{tabular}

efficient owner $e$ is the acquirer, the other that an inefficient owner $i$ is the acquirer. Hence, even an auction with bidding competition among several potential owners may result in inefficient ownership of the state assets. However, when competition in the investment game increases, this will tend to generate efficient ownership. To see this, note that:

$$
\lim _{\rho \rightarrow 0} v_{i e}=\pi_{i}(c, 0)<\lim _{\rho \rightarrow 0} v_{e i}=\pi_{i}(0,0)
$$

where we are modelling increased competition in the investment game as a decrease in the probability of successful greenfield investment $\rho$, due to a larger pool of potential entrants, $M$. Hence, we can state the following proposition:

Proposition 2. Suppose that there exists a threshold probability of greenfield entry $\rho^{*}$ such that $v_{i e}\left(\rho^{*}, \cdot\right)=v_{e i}\left(\rho^{*}, \cdot\right)$. Then, at $\rho>\rho^{*}$, an inefficient owner obtains the state assets, whereas at $\rho<\rho^{*}$, an efficient owner may obtain the state assets.

The proposition thus illustrates that the risk of owners strategically using the auction to limit the production competition is reduced when more owners contemplate entering the market than would be profitable. Consequently, it is important for the authority to attract a sufficient number of potential investors for the market both in the privatization stage as well as in the investment stage. Competition in the privatization stage is not sufficient, there must also be sufficient competition for the whole market. ${ }^{16}$

\footnotetext{
${ }^{16}$ It might be argued that more greenfield entrants could enter the market under inefficient ownership of the former state assets, since product market competition is then weaker. This would decrease the value of having a high cost firm in the market.
} 


\subsubsection{Strengthening competition in the market}

Competition for the market may promote efficiency. Here it assumed that all $M=E+I$ owners enter the market, one by acquisition and the remaining by new investments.As before, we remain in the parameter setting corresponding to that of Region 2 in Figure 3.1(ii). We can then derive the following result:

Proposition 3. (i) Increasing the product market competition beyond duopoly leads to efficient ownership in the Linear Cournot Model, (ii) increasing the product market competition beyond triopoly leads to efficient ownership in the Linear Bertrand Model.

Proof. See, the Appendix.

In the appendix, we show that the main features of the non-linear tendency for an asymmetric market structure to produce higher profits (manifested by the anti-competitive,business-stealing, and direct cost saving effects in Figure 3.1(i)) are also present with more active firms in the product market. However, the strengthened product market competition also promotes an efficient allocation of asset ownership. In the linear Cournot model, triopoly and less concentrated market structures lead to efficient ownership, whereas quadropoly is required to guarantee efficient ownership in the linear Bertrand model. ${ }^{17}$ The reason is that an inefficient ownership of state assets vanishes as this owner cannot make a profit in an environment with several producers with a low marginal cost.

This result is, however, based on the assumption that inefficient and efficient owners are equally efficient in using new assets. While simplifying the analysis, this is a strong assumption. A more realistic assumption is that the efficient owner could use both state assets and new assets more efficiently. As we show in the Appendix, inefficient ownership then extends beyond duopoly in a linear Cournot model (since competition is less intense with competitors being both efficient, as well as, inefficient firms with new assets). However, it is still the case that strengthened product market competition promotes an effective use of the state assets.

\footnotetext{
${ }^{17}$ Proofs are available upon request.
} 
The results in this section thus illustrates that the risk of owners strategically using the auction to limit the production competition is reduced when competition is strong in the product market. Consequently, it is important for the authority to ensure that entry into the market is facilitated, not only to increase the number of the firms in the industry but also to improve the outcome in the privatization.

\subsection{Employment Policies}

In some situations, future commitments to employment after a privatization are negotiated. $^{18}$ Such commitments might imply that production cannot be run as efficiently as otherwise would be the case. Thus, the production costs might increase by such commitment. However, this policy might not only have direct effects, but might also affect the equilibrium market structure. To see this, assume the setting with two owners in section 2 and that we are in the equilibrium where only the non-acquirer invests in period 2 (Region 2 in Figure 3.1) and where the efficient owner obtains the state assets. Suppose now that the government requires future employment commitments which increase the variable production cost when using the state assets. As shown in the Appendix, a small increase in variable production costs might then imply that the inefficient owner obtains the state assets. Since it will be a more harmless competitor, the efficient owner lets it obtain the state assets at a very low price. This implies that the inefficient owner will now abstain from investing in new assets and might therefore reduce its production and possibly also its total employment. The Employment Guarantee can thereby reduce welfare. Accordingly, we have the following results:

Proposition 4. (i) Employment Guarantees in a privatized firm may imply that a less efficient owner obtains the privatized firm and could thereby lead to lower total employment in the market.

\footnotetext{
${ }^{18}$ For example, in Poland, the acquisition of a telecommunication equipment manufacturer by Siemens guaranteed continued employment for an 18-month period. (See World Investment Report, 2000.)
} 
On the other hand, if it is less costly for the inefficient owner to keep the old work force, this type of policy will have the opposite effect.

\section{Concluding discussion}

This paper determines the equilibrium market structure in an emerging market. It is shown that bidding competition in the privatization stage is necessary but not sufficient for having an efficient buyer and thereby an efficient equilibrium market structure. Competition in the ensuing entry stage is also required. Otherwise, one owner can induce another to take the role of the weak owner in the subsequent product market competition, by making concessions in the bidding in the privatization auction. Consequently, it is important that the authority not only ensures that there is competition for the privatized firm but also reduces the pre-investment cost for owners contemplating investing in the liberalized market in general.

The paper also points to the fact that Employment Guarantees can be counterproductive in the sense of implying that a less efficient owner obtains the privatized firm. The intuition is that the Employment Guarantee helps the buyer of the state-assets to "abstain" from investing, thereby creating a less competitive market structure with less total employment. Consequently, it is important that authorities consider all potential investors' incentives for investment when designing investment and employment policies.

The issue of the optimal design of the privatization policy has not been addressed here. The complexity of the externalities involved in the selling of the state assets indicates that informational constraint will be important for deriving optimal policies. A natural step, however, is to explicitly model this restriction and investigate whether selling rules incurring a higher welfare level might be found. 


\section{References}

[1] Chen, Y., 2000, Strategic Bidding by Potential Competitors: Will Monopoly Persist?, "Journal of Industrial Economics," v48, n2, 161-75.

[2] Deneckere, R. and Davidson, C., 1985, "Incentives to Form Coalitions with Bertrand Competition" , Rand Journal of Economics v16, n4, 473-86.

[3] Djankov, S. and Murrell, P., 2002, "Enterprise Restructuring in Transition: A Quantitativ Survey", Journal of Economic Literature, vol. XL, 739-792.

[4] Ghemawat, P., "The Snowball Effect," International Journal of Industrial Organization, 1990, 8, 335-351.

[5] Jehiel, P. and Moldovanu, B., 1996a, "Strategic Nonparticipation," RAND Journal of Economics, Vol. 27, 84-98.

[6] Jehiel, P. and Moldovanu, B., 2000, "License Auctions and Market Structure, Discussion Paper 2530, Center for Economic Policy Research.

[7] Klemperer, P., 2002, "What Really Matters in Auction Design", Journal of Economic Perspective.

[8] Krishna, K., 1993, "Auctions With Endogenous Valuations: The Persistence of Monopoly Revisited," American Economic Review, 83, 147-160.

[9] Megginson, W. L. and Netter, J. M., 2001, "From State to Market: A Survey of Empirical Studies on Privatizations", Journal of Economic Literature, vol. XXXIX, pp. 321-389.

[10] Norbäck, P. J. and Persson, L., 2003, "Privatization and Foreign Competition", forthcoming, Journal of International Economics.

[11] OECD, Corporate Affairs Division, "Recent Privatisation Trends", 2000. 
[12] Porter, M. E., 1998, "Competitive Advantage ", The Free Press.

[13] Schmidt, K., M. and Schnitzer, M., 1997, "Methods of Privatization: Auctions, Bargaining and Give-aways," CEPR Discussion Paper 1541.

[14] UNCTAD, World Investment Report 1998, 1999 and 2000, (United Nations Conference on Trade and Development, Geneva).

[15] Vickers, J and Yarrow, G., 1991, "Economic Perspectives on Privatization", Journal of Economic Perspectives, Vol.5, No. 2, 111-132.

\section{A. Appendix: Solving the investment game}

The solution when the efficient owner obtains the state assets follows directly since not investing $(N)$ is a dominant strategy for the efficient owner. Let us therefore proceed to the case when the inefficient owner obtains the state assets. Making use of the critical investment cost defined in the text, i.e. $\bar{G}_{i, I}^{a}=\pi_{i}^{D}(0,0)-\pi_{i}^{D}(c, 0), \bar{G}_{i, N}^{a}=\pi_{i}^{M}(0)-\pi_{i}^{M}(c)$, $\bar{G}_{e, I}^{n}=\pi_{e}^{D}(0,0)$ and $\bar{G}_{e, N}^{n}=\pi_{e}^{D}(0, c)$, define inequalities 1a-4a for the efficient owner, and inequalities $1 \mathrm{~b}-4 \mathrm{~b}$ for the inefficient owner in table A.1. For each such pair of inequalities, table A.1 provides the associated Nash-equilibria, where the pair of inequalities fulfilled in Figure 2.2(iii) are marked in bold.

Under inequalities $4 \mathrm{a}$ and $4 \mathrm{~b}$, multiple equilibria arise. There is a mixed equilibrium $\{\epsilon, \theta\}$ where owner $e$ invests with probability $\epsilon$ and the inefficient owner invests with probability $\theta$, but also two asymmetric equilibria $\{I, N\}$ and $\{N, I\}$. Assuming away the mixed equilibrium and using risk-dominance, it can be shown that only equilibrium $\{\mathrm{N}, \mathrm{I}\}$ remains.

To see this, suppose that $\{\mathrm{I}, \mathrm{N}\}$ is preferred to $\{\mathrm{N}, \mathrm{I}\}$. Then, according to the criteria of risk-dominance, it must be the case that: 


$$
\begin{aligned}
{\left[\left(\pi_{e}^{D}(0, c)-G\right)-\left(\pi_{e}^{D}(0,0)-G\right)\right]\left[\left(\pi_{i}^{D}(c, 0)-G\right)-\pi_{i}^{M}(c)\right] } & >0 *\left[\pi_{i}^{M}(c)-G-\pi_{i}^{M}(c)\right] \\
{\left[\pi_{e}^{D}(0, c)-\pi_{e}^{D}(0,0)\right]\left[\left(\pi_{i}^{D}(c, 0)-G\right)-\pi_{i}^{M}(c)\right] } & >0
\end{aligned}
$$

where we have used the information in Figure 2.2 (i). However, note that $\pi_{e}^{D}(0, c)-$ $\pi_{e}^{D}(0,0)>0$ holds, and that $\pi_{i}^{D}(c, 0)-G-\pi_{i}^{M}(c)<0$. Hence, it must be that $\{\mathrm{N}, \mathrm{I}\}$ is preferred by the owners.

\begin{tabular}{|c|c|c|c|c|c|}
\hline & & $1 b$ & $2 b$ & $3 b:$ & $4 b:$ \\
\hline & & $G<\bar{G}_{i, I}^{a}$ & $G>G_{i, I}^{a}$ & $G<G_{i, I}^{a}$ & $G>G_{i, I}^{a}$ \\
\hline & & $G<\bar{G}_{i, N}^{a}$ & $G>G_{i, N}^{a}$ & $G>G_{i, N}^{a}$ & $G<G_{i, N}^{a}$ \\
\hline \multirow{2}{*}{$1 a:$} & $G<G_{e, I}^{n}$ & $\{\mathrm{I}, \mathrm{I}\}$ & \multirow{2}{*}{ [Not fulfilled] } & \multirow{2}{*}{ [Not fulfilled] } & $\{\mathrm{I}, \mathrm{N}\}$ \\
\hline & $G<G_{e, N}^{n}$ & Region 1 & & & Region 2] \\
\hline \multirow[t]{2}{*}{$2 a:$} & $G>G_{e, I}^{n}$ & \multirow[t]{2}{*}{ [Not fulfilled] } & $\{\mathrm{N}, \mathrm{N}\}$ & \multirow[t]{2}{*}{ [Not fulfilled] } & \multirow[t]{2}{*}{ [Not fulfilled] } \\
\hline & $G>G_{e, N}^{n}$ & & Region 5 & & \\
\hline \multirow[t]{2}{*}{$3 a:$} & $G<G_{e, I}^{n}$ & \multirow[t]{2}{*}{ [Not fulfilled] } & \multirow[t]{2}{*}{ [Not fulfilled] } & \multirow[t]{2}{*}{ [Not fulfilled] } & \multirow[t]{2}{*}{ [Not fulfilled] } \\
\hline & $G>G_{e, N}^{n}$ & & & & \\
\hline \multirow{4}{*}{$4 a:$} & & \multirow{4}{*}{ [Not fulfilled] } & \multirow{4}{*}{$\begin{array}{c}\{\mathrm{I}, \mathrm{N}\} \\
\text { Region } 4\end{array}$} & \multirow{4}{*}{ [Not fulfilled] } & $\{\mathrm{I}, \mathrm{N}\}$ \\
\hline & $G>G_{e, I}^{n}$ & & & & $\{\mathrm{NH}\}$ \\
\hline & $G<G_{e, N}^{n}$ & & & & र \\
\hline & & & & & Region 3 \\
\hline
\end{tabular}

Table A.1: Solving the investment game when the ineffcient firm $i$ acquires the state assets.

\section{B. Appendix: Proof of Lemma 1}

Let $v_{h}>v_{j}$ without loss of generality. First, consider the equilibrium candidate where firm $i$ acquires the state assets. Consider the equilibrium candidate $\mathbf{b}^{*}$, where $b_{h}^{*}>b_{j}^{*}$, 
$j \neq h$. Let owner $h$ be the owner obtaining the state assets. Note that $b_{h}^{*}>v_{h}$ is a weakly dominated strategy, since no owner will post a bid over its maximum valuation of obtaining the assets. If $b_{h}^{*}<v_{j}$, firm $j$ benefits from deviating to $b_{j}^{* *}=b_{h}^{*}+\varepsilon$, since it then obtains the assets and pays a price for the assets lower than its valuation of obtaining them. Last, consider candidate $b_{h}^{*}=v_{j}, b_{j}^{*}=v_{j}-\varepsilon$. Then, no owner has an incentive to deviate. Thus, this is a Nash equilibrium and the only NE where firm $i$ obtains the assets.

Let us now show that this is the only Nash equilibrium. First, consider the situation where firm $j$ obtains the assets. Consider the equilibrium candidate $\mathbf{b}^{*}$, where $b_{j}^{*}>b_{h}^{*}$, $j \neq h$. But we know that in equilibrium, $b_{j}^{*}<v_{j}$, since firm $j$ otherwise plays a weakly dominated strategy. But if $b_{j}^{*}<v_{j}$, firm $i$ benefits from deviating to $b_{h}^{* *}=b_{j}^{*}+\varepsilon$, since it then obtains the assets and pays a price lower than its valuation of obtaining them. Thus, firm $j$ obtaining the assets is not an equilibrium.

Second, note that the situation where neither firm $i$ nor firm $j$ obtains the assets cannot occur if there is no reservation price at the auction.

\section{Appendix: Deriving the Equilibrium Market Structure}

\section{C.1. Region 1 in table 3.1: $G<G_{i, I}^{a}$}

From Figure 2.2(iii), we note that under inefficient ownership both firms invest greenfield, whereas under efficient ownership, as illustrated in Figure 2.2(iv), only firm $i$ invests. The inefficient firm's valuation is then $v_{i e}=\pi_{i}^{D}(0,0)-G-\left(\pi_{i}^{D}(0,0)-G\right)=0$, whereas the efficient firm's valuation is $v_{e i}=\pi_{e}^{D}(0,0)-\left(\pi_{e}^{D}(0,0)-G\right)=G$. Since $v_{i e}-v_{e i}=-G<0$, this leads to an efficient acquisition at the price $\mathcal{A}=v_{i e}=0$ and the market structure is $M\left(k_{S}, k_{N}\right)$.

C.2. Region 2 in table 3.1: $G_{i, I}^{a}<G<G_{e, I}^{n}, \quad 0<c<c^{\max }$

This is the case discussed in the main text. From Figure 2.2(iii), we note that under inefficient ownership only the efficient firms $i$ invest greenfield, whereas under efficient 
ownership, as illustrated in Figure 2.2(iv), both firms invests. The inefficient firm's valuation is then $v_{i e}=\pi_{i}^{D}(c, 0)-\left(\pi_{i}^{D}(0,0)-G\right)$, whereas the efficient firm's valuation is $v_{e i}=\pi_{e}^{D}(0,0)-\left(\pi_{e}^{D}(0, c)-G\right)$.

\section{C.2.1. Deriving (3.1)}

First, note that:

$$
\begin{aligned}
v_{i e}-v_{e i} & =\pi_{i}^{D}(c, 0)-\left(\pi_{i}^{D}(0,0)-G\right)-\left[\pi_{e}^{D}(0,0)-\left(\pi_{e}^{D}(0, c)-G\right)\right] \\
& =\Pi_{i}(c)-\Pi_{e}(0)
\end{aligned}
$$

where $\Pi_{i}(c)=\pi_{i}^{D}(c, 0)+\pi_{e}^{D}(0, c)+G$ is the aggregate profit under domestic ownership of the state assets and $\left.\Pi_{e}(0)=\pi_{i}^{D}(0,0)+\pi_{e}^{D}(0,0)\right)+G$ is the aggregate profit under foreign ownership. Hence, $c$ only affect's the profits under domestic ownership. To study how $v_{i e}-v_{e i}$ reacts to changes in $c$, we can simply explore the aggregate profits $\Pi_{i}(c)$. Firms' profits under a domestic acquisition are then $\pi_{e}=P\left(q_{e}+q_{i}\right) q_{f}$ and $\pi_{i}=P\left(q_{e}+q_{i}\right) q_{i}-c q_{i}$ and the associated FOCs are :

$$
\begin{aligned}
& \frac{\partial \pi_{e}}{\partial q_{e}}=P+P^{\prime} q_{e}=0 \\
& \frac{\partial \pi_{i}}{\partial q_{i}}=P+P^{\prime} q_{i}-c=0
\end{aligned}
$$

Differentiating (C.2) (C.3) wrt $q_{e}, q_{i}$, and $c$ and solving for yields $\frac{d q_{e}}{d c}=-\frac{P^{\prime}+P^{\prime \prime} q_{e}}{D}>0$, $\frac{d q_{i}}{d c}=\frac{2 P^{\prime}+P^{\prime \prime} q_{e}}{D}<0$ and $\frac{d Q}{d c}=\frac{P^{\prime}}{D}<0$, where $D=P^{\prime}\left[3 P^{\prime}+P^{\prime \prime} Q\right]>0$ and $Q=q_{e}+q_{i}$. We can then define the aggregate profits as a function of $c$ :

$$
\Pi_{i}(c)=\pi_{e}\left(q_{e}(c), q_{i}(c), c\right)+\pi_{i}\left(q_{e}(c), q_{i}(c), c\right)
$$

Taking the total derivative in $c$ and using (C.2) and (C.3), (C.4) can be written as:

$$
\frac{d \Pi_{i}}{d c}=P^{\prime} q_{e} \frac{d q_{i}}{d c}+P^{\prime} q_{i} \frac{d q_{e}}{d c}-q_{i}
$$

Also noting that $\frac{d Q}{d c}=\frac{d q_{e}}{d c}+\frac{d q_{i}}{d c}$ must hold, (C.5) can be rewritten as:

$$
\frac{d \Pi_{i}}{d c}=P^{\prime} q_{e} \frac{d Q}{d c}+c \frac{d q_{e}}{d c}-q_{i} .
$$




\section{C.2.2. Proving Lemma 2}

First, we rewrite $\Pi_{i}(c)$ by inserting $\frac{d q_{e}}{d c}=-\frac{P^{\prime}+P^{\prime \prime} q_{e}}{D}>0, \frac{d q_{i}}{d c}=\frac{2 P^{\prime}+P^{\prime \prime} q_{e}}{D}<0$ and $\frac{d Q}{d c}=$ $\frac{P^{\prime}}{D}<0$, where $D=P^{\prime}\left[3 P^{\prime}+P^{\prime \prime} Q\right]>0$ into (C.5). (C.5) can then be written as

$$
\frac{d \Pi(c)}{d c}=\left(\frac{2 P^{\prime}+P^{\prime \prime} q_{e}}{3 P^{\prime}+P^{\prime \prime} Q}\right)\left(q_{e}-q_{i}-\frac{2 P^{\prime}+P^{\prime \prime} Q}{2 P^{\prime}+P^{\prime \prime} q_{e}} q_{i}\right)
$$

We then proceed by deriving the following Lemmas:

Lemma 3. (i) $\frac{d \Pi_{i}}{d c}(0)<0$, (ii) $\Pi_{i}\left(c^{\max }\right)>\Pi_{i}(0)$, and (iii) $\Pi_{i}(c)$ has a global minimum $c$ for $c \in\left[0, c^{\max }\right]$.

Proof. If demand $P(Q)$ is concave $\beta_{Q} \geq 0$ and $\beta_{q_{e}} \geq 0$, since $P^{\prime}<0$ and $P^{\prime \prime} \leq 0$. Then:

(i) At $c=0$, we must have $q_{e}=q_{i}$, which implies that $\frac{d \Pi_{i}}{d c}(0)=-q \frac{2+\beta_{Q}}{3+\beta_{Q}}<0$.

(ii) At $c=c^{\max }$, owner $i$ becomes a monopolist and thus, $\Pi_{i}\left(c^{\max }\right)>\Pi_{i}(0)$.

(iii) Define $\tilde{c}$ by $\frac{d \Pi_{i}}{d c}(\tilde{c})=0$.

Once more, note that $\frac{d \Pi_{i}}{d c}(0)<0$. Also, note that $\lim _{\varepsilon \rightarrow 0} \frac{d \Pi_{i}}{d c}\left(c^{\max }-\varepsilon\right)>0$. Then, since $q_{e}-$ $q_{i}$ is monotonically increasing in $c$, whereas $\frac{2 P^{\prime}+P^{\prime \prime} Q}{2 P^{\prime}+P^{\prime \prime} q_{e}} q_{i}$ is strictly positive and monotonically decreasing in $c$, we know that the $\operatorname{sign}\left(\frac{d \Pi_{i}}{d c}\right)$ only changes once and hence, the aggregate profit $\Pi_{i}(c)$ has a unique global minimum at $c=\tilde{c}$.

It then follows that $v_{i e}-v_{e i}<0$ for $c<c^{*}$, leading to an efficient acquisition at the price $\mathcal{A}=v_{i e}$ and to a market structure $M\left(k_{S}, k_{N}\right)$. It also follows that, that $v_{i e}-v_{e i}>0$ for $c>c^{*}$, leading to an inefficient acquisition at the price $\mathcal{A}=v_{i e}$ and to a market structure $M\left(k_{N}, k_{S}\right)$.

\section{C.2.3. Investigating net profits}

Here, we derive Figure 3.1 (iii) algebraically.

First, consider the case when $c>c^{*}$. For the inefficient firm, note that:

$$
\begin{aligned}
\Lambda_{i} & =\pi_{i}^{D}(c, 0)-\mathcal{A} \\
& =\pi_{i}^{D}(c, 0)-\left[\pi_{e}^{D}(0,0)-\left(\pi_{e}^{D}(0, c)-G\right)\right] \\
& =\Pi_{i}(c)-\Pi_{e}(0)+\pi_{i}^{D}(0,0)-G
\end{aligned}
$$


where we may directly note that: $\Lambda_{i}>\pi_{i}^{D}(0,0)-G$ since we have shown above that $\Pi_{i}(c)-\Pi_{e}(0)>0$ for $c>c^{*}$. Moreover, since $\frac{d \Pi_{i}(c)}{d c}>0$ for $c>c^{*}$, it also holds that $\frac{d \Lambda_{i}}{d c}>0$. Turning to the efficient firm:

$$
\Lambda_{e}=\pi_{e}^{D}(0, c)-G>\pi_{e}^{D}(0,0)-G
$$

and it also follows that $\frac{d \Lambda_{e}}{d c}=\frac{d \pi_{e}^{D}(0, c)}{d c}>0$.

Finally, take the case when $c<c^{*}$. Then, note that:

$$
\begin{aligned}
\Lambda_{e}= & \pi_{e}^{D}(0,0)-\mathcal{A} \\
= & \pi_{e}^{D}(0,0)-\left[\pi_{i}^{D}(c, 0)-\left(\pi_{i}^{D}(0,0)-G\right)\right] \\
= & \pi_{e}^{D}(0,0)-\pi_{i}^{D}(c, 0)+\pi_{i}^{D}(0,0)-G> \\
& \pi_{e}^{D}(0,0)-G
\end{aligned}
$$

since $\pi_{e}^{D}(0,0)-G=\pi_{i}^{D}(0,0)-G$. It also holds that $\frac{d \Lambda_{e}}{d c}=-\frac{d \pi_{i}^{D}(c, 0)}{d c}>0$. Finally, looking at the inefficient firm, we have simply have $\Lambda_{i}=\pi_{i}^{D}(0,0)-G$.

\section{C.2.4. Linear Bertrand and Cournot models}

In this section, we show that inefficient domestic acquisitions also appear in a Bertrand model with linear demand due to Deneckere and Davidson (1985). For comparison, we also add a linear Cournot model. The proof proceeds as follows: Above, we have shown this to hold using a strictly concave demand and assuming Cournot competition with homogenous goods. In table C.1 below, we show that this will hold both under Bertrand and Cournot competition. We first define demand in each model, where $a$ is the willingness to pay, $b$ is the slope of the inverse demand curve under Cournot competition and $\gamma$ shows the degree of product differentiation under Bertrand competition (i.e. $\gamma=0$ implies that domestic and foreign goods are unrelated, $\gamma=\infty$ that they are perfect substitutes). We then display firms' reduced form profits, $\pi_{h}^{D}$ for $h=\{i, e\}$, as functions of the demand characteristics and marginal costs under duopoly. We also repeat the assumptions on marginal costs for the different types of firms made in the text. 
Having derived the profit-expressions, we calculate the critical greenfield cost $\bar{G}_{i, I}^{b}=$ $\pi_{i}^{D}(c, 0)-\pi_{i}^{D}(0, c)$ and the critical trade $\operatorname{cost} c^{\max }$ for both models (defined as $q_{i}^{D}\left(c^{\max }, 0\right)=$ $0)$. From these expressions, it can be shown that $\bar{G}_{i, I}^{a}(c)$ is increasing and concave in $c$, for $c<c^{\max }$, and $\bar{G}_{i, I}^{a}(c)=\pi_{h}^{D}(0,0)$ and $\frac{d \bar{G}_{i, I}^{a}(c)}{d c}=0$ for $c>t^{\max }$. This reproduces $\bar{G}_{i, I}^{a}(c)$ in the shadowed area in the middle panel of Figure 3.1 (ii).

From the expressions in table 1 , it is clear that $v_{i}-v_{e}$ is a strictly convex function of $c$, with a single minimum $\tilde{c}>0$ for both models. There is also a $c^{*}>0$ for which $c>c^{*}$ implies that $v_{i}>v_{e}$, whereas $c<c^{*}$ implies that $v_{i}<v_{e}$. It is also clear that $0<\tilde{c}<c^{*}<c^{\max }$ holds in the Cournot model, and that this condition is also fulfilled in the Bertrand model, given that domestic and foreign goods are sufficiently close substitutes (i.e. parameter $\gamma$ is sufficiently large).

\section{C.3. Region 3 in table 3.1: $G_{e, I}^{n}<G<G_{i, N}^{a}$}

From Figure 2.2(iii), we note that under inefficient ownership there are miltiple equilibria in the investment game. However, we showed in Section A using risk-domince $\{\mathrm{N}, \mathrm{I}\}$ is selected. Hence, only the efficient firms $i$ invest greenfield, whereas under efficient ownership, as illustrated in Figure 2.2(iv), no firm invests. The inefficient firm's valuation is then $v_{i e}=\pi_{i}^{M}(0)-G$, whereas the efficient firm's valuation is $v_{e i}=\pi_{e}^{M}(0)$.Since $v_{i e}-v_{e i}=-G<0$, this leads to an efficient acquisition at the price $\mathcal{A}=v_{i e}$ and the market structure is $M\left(k_{S}, 0\right)$.

\section{C.4. Region 4 in table 3.1: $G_{e, I}^{n}<G<G_{i, N}^{a}$}

From Figure 2.2(iii), we note that under inefficient ownership only the efficient firms $e$ invest greenfield, whereas under efficient ownership, as illustrated in Figure 2.2(iv), no firm invest. The inefficient firm's valuation is then $v_{i e}=\pi_{i}^{D}(c, 0)$, whereas the efficient firm's valuation is $v_{e i}=\pi_{e}^{M}(0)-\left(\pi_{e}^{D}(0, c)-G\right)$. Since $v_{i e}-v_{e i}=\pi_{i}^{D}(c, 0)+\left(\pi_{e}^{D}(0, c)-G\right)-$ $\pi_{e}^{M}(0)<0$, this leads to an efficient acquisition at the price $\mathcal{A}=v_{i e}$ and the market structure is $M\left(k_{S}, 0\right)$. 


\section{C.5. Region 5 in table 3.1: $G>G_{e, N}^{n}$}

From Figure 2.2(iii) and Figure 2.2(iv), it is clear that investment never takes place. The inefficient firm's valuation is then $v_{i e}=\pi_{i}^{M}(c)$, whereas the efficient firm's valuation is $v_{e}=\pi_{e}^{M}(0)$. Since $v_{i e}-v_{e i}=\pi_{i}^{M}(c)-\pi_{e}^{M}(0)<0$, this leads to an efficient acquisition at the price $\mathcal{A}=v_{i e}$ and the market structure is $M\left(k_{S}, 0\right)$.

\section{Proof of Proposition 3}

It is straightforward to extend the analysis and allow for more than duopoly in the product market interaction. For the case of Cournot competition with concave demand and assuming parameter values corresponding to Region 2 in Figure 3.1 (ii), where only the non-acquirer invests in new assets, it can be checked that (C.7) can be re-written as:

$$
\frac{d \Pi(c)}{d c}=\left(\frac{(\mathcal{N}+1) P^{\prime}+P^{\prime \prime} q_{e}}{(\mathcal{N}+2) P^{\prime}+P^{\prime \prime} Q}\right)\left(q_{e}-q_{i}-\frac{2 P^{\prime}+P^{\prime \prime} Q}{(\mathcal{N}+1) P^{\prime}+P^{\prime \prime} q_{e}} q_{i}+\frac{(N-1) P^{\prime \prime} q_{q}}{(\mathcal{N}+1) P^{\prime}+P^{\prime \prime} q_{e}} q_{e}\right)
$$

where $\mathcal{N}$ is the number of (investing) competitors the acquirer is facing. Again, noting that $\Pi(c)=v_{i e}-v_{e i}$ it can be shown that inefficient ownership occurs for when $c$ is sufficiently high, given that demand $P(Q)$ is not too concave. That is, $\Pi(c)$ exhibits the same convex shape as in Figure 3.1 (i) so that Lemma 3 also extends beyond duopoly.

However, the above calculation assumes that the acquirer remains active on the market despite high production costs. It can then be checked that adding more owners removes inefficient ownership in the Linear Cournot model in table C.1. More specifically, with $\mathcal{N}$ owners investing in new assets in addition to the non-investing acquirer, it can be checked that $c^{*}, \tilde{c}, c^{\max }$ in Figure 3.1 becomes $c^{*}=\frac{2 \mathcal{N} a}{2 N+N^{2}+2}, \tilde{c}=\frac{\mathcal{N a}}{2 N+N^{2}+2}$ and $c^{\max }=\frac{\left(\mathcal{N}^{2}-2\right) a}{N+1} a$, which implies that inefficient ownership does not extend into triopoly, since:

$$
c^{\max }-c^{*}=\frac{\left(2-\mathcal{N}^{2}\right)}{\left(2 \mathcal{N}+\mathcal{N}^{2}+2\right)(\mathcal{N}+1)}<0 \text { iff } \mathcal{N}>1
$$

Next, we discuss adding more owners to the Bertrand model in table C.1. First, assume that $\mathcal{N}=2$ owners invest in new assets while the inefficient owner does not invest. The 
same calculations yield $c^{*}=\frac{\left(54 \gamma+21 \gamma^{2}+\gamma^{3}+36\right)}{216 \gamma+135 \gamma^{2}+27 \gamma^{3}+2 \gamma^{4}+108} 6 a$ and $c^{\max }=\frac{3 a(2 \gamma+3)}{9 \gamma+\gamma^{2}+9}$, where it can be checked that $c^{\max }>c^{*}$ if the degree of product differentiation is sufficiently high, i.e. if $\gamma>18$. This shows that inefficient ownership extends into triopoly. However, investigating quadropoly, i.e. $\mathcal{N}=3$, this does not allow for inefficient ownership, since it can be shown that $c^{\max }=\frac{32 a+28 a \gamma}{40 \gamma+9 \gamma^{2}+32}$ and $c^{*}=\frac{1024 a+2048 a \gamma+1200 a \gamma^{2}+168 a \gamma^{3}}{1280 \gamma+1096 \gamma^{2}+372 \gamma^{3}+45 \gamma^{4}+512}$, which implies that:

$$
c^{\max }-c^{*}=-4 \frac{\left(1152 \gamma+824 \gamma^{2}+192 \gamma^{3}+9 \gamma^{4}+512\right)(7 \gamma+8) a}{\left(1280 \gamma+1096 \gamma^{2}+372 \gamma^{3}+45 \gamma^{4}+512\right)\left(40 \gamma+9 \gamma^{2}+32\right)}<0 .
$$

However, a strong assumption in the above text is that inefficient and efficient owners are equally efficient in using new assets. A more realistic assumption is that the efficient owner could use both state assets and new assets more efficiently. To show the effect, assume that an efficient owner faces a zero marginal cost irrespective of using new or state assets, but that inefficient owners face a marginal cost of $c>0$ when using state assets but a marginal cost of $\gamma c$ when using new assets, where $0<\gamma<1$. Hence, in this setting, inefficient owners are less able to use both state and new assets, which is reasonable. Again, we assume that the fixed costs are too high for the inefficient owner to invest in new assets when acquiring (which may or may not yield a lower marginal cost than $\gamma c$ ). Assuming one efficient owner and two inefficient owners, we can then derive $\tilde{c}=\frac{a}{3 \gamma+5}, c^{*}=2 \frac{a}{3 \gamma+5}$, $c^{\max }=\frac{a}{3-\gamma}$, which implies

$$
c^{\max }-c^{*}=a \frac{5 \gamma-1}{(3-\gamma)(3 \gamma+5)}>0 \text { if } \gamma>\frac{1}{5} .
$$

Hence, this example shows that assuming a "symmetric" asymmetry between efficient and inefficient owners implies that inefficient ownership in the Linear Cournot model extends to triopoly.

\section{E. Proof of Proposition 4}

To illustrate the effect of employment guarantees, suppose that this causes the marginal cost for the acquirer, irrespective of type, to increase by some constant $\alpha$. All other 
assumptions remain unchanged. It can then be shown that under the linear Cournot model:

$$
v_{i e}-v_{e i}=\frac{1}{9} c(5 c+10 \alpha-2),
$$

which implies that $\left.c^{*}\right|_{\alpha>0}=\frac{2 a}{5}-2 \alpha<\left.c^{*}\right|_{\alpha=0}=\frac{2 a}{5}$. 
Table C.1: Deriving the equilibrium market structure under linear Cournot and Bertrand duopoly models. in Region 2.

\section{Cournot:}

Bertrand:

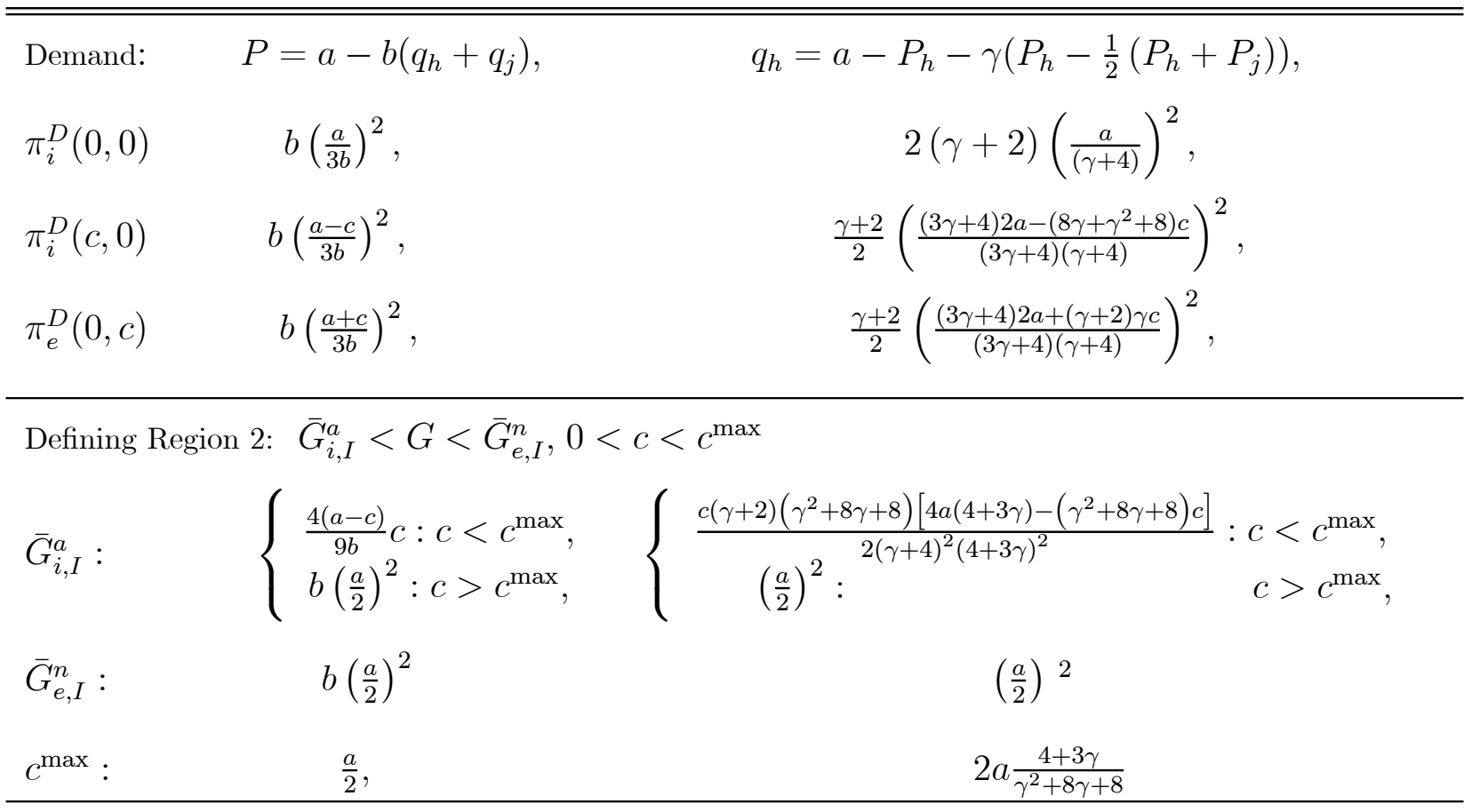

Comparing valuations in Region 2:

$$
\begin{aligned}
& v_{i e}-v_{e i}:-\frac{(2 a-5 c)}{9 b} c\left\{\begin{array} { c } 
{ < 0 : c < c ^ { * } , } \\
{ > 0 : c > c ^ { * } , }
\end{array} \quad \frac { c ( \gamma + 2 ) [ ( \gamma ^ { 4 } + 1 0 \gamma ^ { 3 } + 4 2 \gamma ^ { 2 } + 6 4 \gamma + 3 2 ) c - 4 a ( 4 + 3 \gamma ) ^ { 2 } ] } { ( \gamma + 4 ) ^ { 2 } ( 4 + 3 \gamma ) ^ { 2 } } \left\{\begin{array}{l}
<0: c<c^{*}, \\
>0: c>c^{*},
\end{array}\right.\right. \\
& c^{*}: \quad \frac{2 a}{5}, \\
& \tilde{c}: \quad \frac{a}{5}, \\
& \text { Note: } \quad 0<\tilde{c}<c^{*}<c^{\max }, \quad 0<\tilde{c}<c^{*}<c^{\max }: \gamma \gtrsim 4 \text {. }
\end{aligned}
$$

